\title{
Cancer in Spain: future perspectives
}

When called upon to write an editorial for a journal of oncology as part of my responsibilities as the Director of the Carlos III Health Institute (ISCIII), there are a number of areas that I could focus on, including public health concerns and cancer as a disease responsible for much morbidity and mortality in Spain (second ranked after cardiovascular diseases).

Among the public health topics related with cancer is information compilation. Partial information is available on the situation of cancer in different regions of Spain, but we do not yet have the national aggregated tumor registries that are a fundamental tool for planning effective strategies against cancer. However, the basic elements for such systems have been designed and, with the help of the National Center of Epidemiology and Health Information of the Carlos III Health Institute and the autonomic communities of Spain, we should be able to meet this need. Therefore, this health care policy goal will undoubtedly soon become a reality.

Cancer is a disease, with a complex pathophysiology and mechanisms of action, and much remains to be learned both about the disease itself and its therapy. We need to analyze the current state of investigation in Spain, particularly cancer research.

Spain has not been known for its scientific contributions in recent decades. Nonetheless, Spanish scientists work all over the world and some of them have earned recognition and awards of the highest rank. At present, Spain is in a situation in which it is difficult to compete for research funds from institutions that have the means and desire to invest in research.

Fortunately, present circumstances suggest that the necessary changes are taking place. The Spanish economy is the strongest it has been in years. Moreover, President José María Aznar's government seems to have taken note that, if Spain wants to sit in a firstclass seat on the train of modern progress, we must actively support research and development. The government's commitment is evident in the just created Ministry of Science and Technology, and in the 2000-2003 National Plan for Research, Development and Technological Innovation that has been recently made public.

This Plan, which many consider insufficient in terms of investment, prioritizes the areas in which Spain should be present, particularly biomedical research. Within this field, disciplines with special applications to cancer research occupy preferential positions.

The Carlos III Health Institute is trying to develop a scientifically competitive national infrastructure for work in the area of the prevalent infectious and chronic diseases. The institute aims to serve as a reference for other, equally valid, efforts, and to help achieve the necessary critical mass and capacity for such efforts. One of our first achievements in this campaign is the Carlos III National Oncological Research Center (CNIO), directed by Mariano Barbacid, which has been planned as a focus for the cooperative efforts of Spanish and non-Spanish groups. The activities of the center have already begun and it is expected to be fully operative within a year. This center was designed to meet the challenges and goals of acquiring knowledge of carcinogenesis mechanisms and their genetic conditionants, discovering new preventive and therapeutic strategies, and providing support services to clinicians, who need information and biomolecular guidelines for patient management.

Work at the center is based on modern concepts that will motivate the incorporation of experienced and well-prepared researchers and attract younger research aspirants who will find an opportunity to acquire competitive training.

We are certain that our efforts, and the new projects that will inevitably arise from them, will attract public and private investment funds for research in Spain, particularly in an area as dynamic as is the oncology.

Public institutions should do their part to create an attractive investment climate. The present government has taken the first steps in this direction and we will all have to help open the way. The Spanish research community, for its part, must continue to keep up its demands and take advantage of the opportunities that become available.

José Antonio Gutiérrez Fuentes Director. Instituto de Salud Carlos III. Madrid. 